\title{
NUTRITIONAL RESEARCH AND INTENSIVE NUTRITIONAL COUNSELLING OF THE CHRONIC KIDNEY DISEASE PATIENTS AFTER KIDNEY TRANSPLANTATION
}

\author{
Limdia KiIsK ${ }^{1}$, Helje KaArma ${ }^{1}$, Mai Ots-Rosenberg ${ }^{2}$ \\ ${ }^{1}$ University of Tartu, Institute of Anatomy, Centre for Physical Anthropology, \\ Tartu, Estonia \\ ${ }^{2}$ University of Tartu, Department of Internal Medicine, Tartu, Estonia
}

\begin{abstract}
Background: Dietology treatment is the one of the foundation stones in the complex treatment of the chronic kidney disease (CKD) patients together with all other treatments. The dietary intervention plays an important role to determine the effects to a decrease of metabolic abnormalities.

Aim: The aim of the long-term study was to monitor nutritional parameters in the post-transplant period.

Subjects and methods: We studied 28 clinically stable consecutive nondiabetic kidney transplant patients: 12 males at the age of $42.8 \pm 16.1$ years, and 16 females at the age of $47.0 \pm 14.9$ years. Intensive nutritional counselling and dietary consultation by a dietitian were carried out for all the studied patients during one and a half years after the kidney transplantation. Initial data were compared with the results obtained at the end of the study. During the 3-days dietary records analysis and counselling of CKD patients, giving answers to their questions about their food and portion sizes, the dietitian used the standards portion book with many photographs.

Results: The consumption of vegetables and fruit was modest compared to Estonian food and nutrition recommendations. The food frequency questionnaire revealed that the patients consumed different foodstuffs at different frequencies, but there was a tendency to excessive consumption of foodstuffs rich in proteins and carbohydrates. To consumption of fat-rich foodstuffs a tendency of decrease was found.
\end{abstract}


Conclusion: An intensive nutritional counselling and healthy diet, avoiding excessive amounts of alcohol as well as regular exercise can help to reduce the chance of developing of chronic transplant nephropathy.

Keywords: kidney transplant patients, nutritional research, nutritional counselling

\section{INTRODUCTION}

Nutritional counselling is performed by the dietician who considers the patient's age, gender, the stage of chronic kidney damage, body build, the twenty-fourhour need for food energy and nutrients, the patient's eating habits.

Dietology treatment is the one of the foundation stones in the complex treatment of the chronic kidney disease (CKD) patients together with all other treatments. The patients with the transplanted kidney are considered also CKD patients [1]. The dietary intervention plays an important role to determine the effects to a decrease of metabolic abnormalities. Physical activity is one aspect of the obesity epidemic, as diet and nutrition are also considered significant factors: of the combination of physical activity and diet modification. The physician or registered dietitian visits during the initial of therapy and must make the patients change his or her dietary habits [3].

In CKD patients nutritional counselling must consider a systematized list of diets. This created system allows achieving individual patient's counselling which considers the patient's disease, the type of body build and the peculiarities of metabolism, the made clinical analyses. The codified system of ordinary foods and diets has been installed into the database which takes into consideration the specific features of treatment and the nutritional needs of the hospital and outpatient departments. Two main methods have been accepted in nutrition research: the food frequency questionnaire (FFQ) and the 3-day nutrition diary. The FFQ lists specific foods and ask the participant if they eat them and if so how often and how much they eat $[3,4,5]$. Dietary records are typically obtained for 3 or 4 days [3]. The dietary record has the potential for providing quality data on the type and amount of food consumed, especially if the record is completed as the foods are consumed [3]. 24-hour recall can not to be used for scientific studies and clinical routine $[1,3]$. This method requires only short-term memory, when the 24 -hour recall can be conducted in person or by telephone with similar results [3]. The author of the thesis has worked out a systematized list of diets and compiled a collection of articles which takes into consideration contemporary principles of feeding treatment. The names and indications of the nomenclature of diets and the respective recommendations 
for the consumption of daily energy and basic nutrients are given in the handbook "Ravitoitlustamine" ("Treatment diets") [6].

The author of the thesis has been the main consultant in the developing and implementation of the system of diets for these programs. Since November 14, 2002 the unified system of diets applied in the hospitals of Tartu began to be used in all the medical institutions of the Republic of Estonia Regulation no 131, Estonian Ministry of Social Affairs [7]. The created system allows achieving the individual patient's counselling which considers the patient's disease, the type of body build and the peculiarities of metabolism, the made clinical analyses. The codified system of ordinary foods and diets has been installed into the database which takes into consideration the specific features of treatment and the nutritional needs of the hospital and outpatient departments.

The aim of the long-term study was to monitor nutritional parameters in the post-transplant period.

\section{MATERIAL AND METHODS}

We studied 28 clinically stable consecutive non-diabetic kidney transplant patients: 12 males at the age of $42.8 \pm 16.1$ years, and 16 females at the age of $47.0 \pm 14.9$ years. The kidney transplantation was performed at the Tartu University Hospital.

All the measurements including anthropometry, densitometry, biochemistry, the food frequency questionnaire (FFQ) and the 3-days dietary records analysis were carried out. The data of anthropometry, biochemistry and the 3-days dietary records analysis were performed in patients twice: one and a half years after the cadaveric kidney transplantation the first measurements, and then, three years after the kidney transplantation follow-up (FU) measurements. Densitometry was performed once three years after the transplantation.

Intensive nutritional counselling and dietary consultation by a dietitian were carried out for all the kidney transplant patients during one and a half years after the kidney transplantation. Initial data were compared with the results obtained at the end of the study. A special FFQ, compiled by the Centre of Physical Anthropology at the the University of Tartu, was used in the current study for socio-economic, physical activity and nutrition research, including 128 foods [4].

The consumption of energy and main nutrients content in 3-day menus of kidney transplant patients was calculated and analyzed with Finnish food composition database program Micro-Nutrica Nutritional Analysis. This adapted 
version was used in Estonia and is used for analysing foods and menus in treatment and care centres, also for drawing up personal menus and comparing nutritional recommendations for different gender and age groups. In calculating menus it is possible to use those beside the Estonian databases guidelines $[6,9,10]$. All the data were compared with the Estonian Nutrition Recommendations [10]. During the 3-days dietary records analysis and counselling of CKD patients, giving answers to their questions about their food and portion sizes, the dietitian used the standards portion book with many photographs $[1,2,6,8]$.

\section{RESULTS AND DISCUSSION}

\section{Lifestyle}

Our study of the FFQ revealed that the patients consumed different foodstuffs at different frequencies, but there was a tendency to excessive consumption of foodstuffs rich in proteins and carbohydrates. After nutritional counselling a tendency of decrease of the consumption of fat-rich foodstuffs was shown in our study. The consumption of vegetables and fruit was modest compared to Estonian food and nutrition recommendations [10]. Guida and co-authors indicated that in kidney transplant patient's intensive dietary intervention on metabolic abnormalities and nutritional status after renal transplantation associated with a reduction in BW and lower plasma levels of cholesterol, triglycerides and glucose [11]. Our FFQ data indicated that the socio-economic situation of the studied CKD patients was poor in $17 \%$ of men and $13 \%$ of women, satisfactory in $75 \%$ of men and $69 \%$ of women, and only $8 \%$ of men and $19 \%$ of women considered their economic status good. Patients' occupations and the working load reflect physical activity (PA). Data analysis indicated that $2 / 3$ of male and $2 / 3$ of female patients did not work as they were categorized as disabled, and $1 / 3$ of subjects worked either constantly or sometimes, either fullor part-time. KDIGO 2012 Clinical Practice Guideline for the Evaluation and Management of Chronic Kidney Disease recommended that people with CKD be encouraged to undertake physical activity compatible with cardiovascular health and tolerance (aiming for at least 30 minutes 5 times per week) achieve a healthy weight (BMI 20 to 25 , according to country specific demographics), and stop smoking $[1,3]$. 


\section{Food energy}

Our 3-day dietary record showed that the average general amount of consumed food energy in the male and female groups diurnally in males non-significantly decreased in the follow-up (at the beginning $2.690 \mathrm{kcal}$ to FU $2.425 \mathrm{kcal}$ ), and in females significantly increased in the follow-up (at the beginning $2.028 \mathrm{kcal}$ to FU $2.353 \mathrm{kcal}$ ), but remained in the limits higher of the recommended daily consumption of food mean energy from the Estonian Nutrition Recommendations reference energy content $2.000 \pm 150 \mathrm{kcal}$ [10]. The daily average food energy content was decreased non-significantly at $265 \pm 176 \mathrm{kcal}$ (min $64 \mathrm{kcal}$, max $765 \mathrm{kcal}$ ) and remained within the normal level in the male group in FU. In the female group the daily average energy content was increased significantly at $325 \pm 22 \mathrm{kcal}$ ( $\min 252 \mathrm{kcal}$, max $292 \mathrm{kcal}$ ) and had a tendency to increase in FU compared within recommended level. The average food energy content per $\mathrm{kg}$ of $\mathrm{BW}$ ( $\mathrm{kcal} / \mathrm{kgBW} /$ day) decreased significantly in male and increased significantly in female CKD patients groups and remained within the normal level.

\section{Dietary protein}

After intense dietary counselling the mean consumption of dietary proteins intake in male patients in the 3-day menus decreased non-significantly in the follow-up $(106.7 \pm 22.4 \mathrm{~g}$, to $91.6 \pm 10.7 \mathrm{~g}$ in FU), and in female patients the dietary protein intake increased significantly in the follow-up (79.6 $\pm 19.7 \mathrm{~g}$, to $89.2 \pm 19.5 \mathrm{~g}$ in FU). The daily average dietary protein intake (g) decreased non-significantly in male patients at the 106.7 to $91.6 \mathrm{~g}$, but increased significantly in female patients at $79.6 \mathrm{~g}$ to $89.2 \mathrm{~g}$. The daily average food proteins intake in $\mathbf{g} / \mathbf{B W}$ decreased significantly in male CKD patients at 1.5 to $1.1 \mathrm{~g} / \mathrm{kg}$, and in female patients was unchanged in follow-up (1.2 g/kg). KDIGO 2012 Clinical Practice Guideline for the Evaluation and Management of Chronic Kidney Disease suggest lowering protein intake and avoid high protein intake $(>1.3 \mathrm{~g} / \mathrm{kg} /$ day) in adults with CKD at risk of progression [1]. Bernard and other authors have been indicated that restriction in dietary protein intake may be a useful strategy in slowing the progression of CKD $[12,13,14,15]$.

\section{Dietary fat and cholesterol}

The daily average food fats ( $\mathrm{g}$ ) content decreased non-significantly in male CKD patients at the 101 grams to 88 grams, and increased non-significantly in female patients at the 76 grams to 88 grams and remained within the normal level [4]. 
Consumption of the food cholesterol was increased significantly in female CKD patients at $271 \mathrm{mg}$ to $360 \mathrm{mg}$ but decreased non-significantly in male patients. Lopes and co-authors performed during the study the dietary intervention which was completed as 3-day food record and indicated that the mean total cholesterol and S-LDL cholesterol decreased statistically significantly for males, but not in female kidney transplant patients [16]. Hines was found that serum lipids levels can improve after nutritional counselling and depends from patient's food habits after counselling. Diets high in saturated fatty acids and trans fatty acids increase S-LDL-cholesterol [17].

\section{Carbohydrates}

Food carbohydrates intake significantly increased in female patients and remained in FU $293 \mathrm{~g}$ in day (50\% carbohydrates of food energy). In male patients food carbohydrates non-significantly decreased during FU (312 g, $51 \%$ of carbohydrates of food energy) and remained within the normal level. KDIGO 2012 Clinical Practice Guideline for the Evaluation and Management of Chronic Kidney Disease suggest that people with CKD, glycemic control should be part of a multifactorial intervention [1]. Zelle and co-authors indicated that lifestyle factors play a role in post-transplant BW gain. Weight gain ranged between $-2.4 \mathrm{~kg}$ and $19.5 \mathrm{~kg}$ and was largely due to increase in body fat, and kidney transplant patients who remained body fat stable, showed more daily physical activity, tended to consume less energy from drinks and dairy, consumed less mono- and disaccharides and ate more vegetables compared with those who gained body fat [18].

\section{Sodium and potassium}

The average sodium content in food decreased non-significally in all patients: in male patients at $2.752 \mathrm{mg}$ to $2.300 \mathrm{mg}$ ( $\mathrm{min} 1,488 \mathrm{mg}$ in FU), and in female kidney transplant patients at $2.240 \mathrm{mg}$ to $2.494 \mathrm{mg}$ (min $1.642 \mathrm{mg}$ in FU). The average potassium content in food decreased non-significally in male patients at $3.920 \mathrm{mg}$ to $3.843 \mathrm{mg}$ ( $\mathrm{min} 3.096 \mathrm{mg}$ in FU), and increased non-significantly in female kidney transplant patients at $2.988 \mathrm{mg}$ to $3.579 \mathrm{mg}$ ( $\mathrm{min} 1.805 \mathrm{mg}$ in FU). KDIGO 2012 Clinical Practice Guideline for the Evaluation and Management of Chronic Kidney Disease recommended people with CKD lowering salt intake to $<2 \mathrm{~g}$ per day of sodium (corresponding to $5 \mathrm{~g}$ of sodium chloride) in adults, unless contraindicated $[1,19]$. 


\section{Calcium, phosphorus, magnesium, iron}

Consumption of the food calcium was increased significantly in female CKD patients at $732 \mathrm{mg}$ to $915 \mathrm{mg}$, but decreased non-significantly in male patients at $1.221 \mathrm{mg}$ to $1.022 \mathrm{mg}$. The average phosphorus content in food decreased non-significally in male patients at $2.046 \mathrm{mg}$ to $1.789 \mathrm{mg}$ (min $1.471 \mathrm{mg}$ and $\max 2.378 \mathrm{mg}$ in FU), and increased significantly in female kidney transplant patients at $1.433 \mathrm{mg}$ to $1.616 \mathrm{mg}$ ( $\mathrm{min} 1.130 \mathrm{mg}$ and $\max 2.321 \mathrm{mg}$ in FU). The average magnesium content in food decreased significally in male patients at $455 \mathrm{mg}$ to $398 \mathrm{mg}$ ( $\mathrm{min} 332 \mathrm{mg}$ and $\mathrm{max} 553 \mathrm{mg}$ in $\mathrm{FU}$ ), and in female patients non-significantly little increased at $326 \mathrm{mg}$ to $346 \mathrm{mg}$ ( $\mathrm{min} 223 \mathrm{mg}$ and $\max$ $486 \mathrm{mg}$ in $\mathrm{FU}$ ). The food iron average consumption in CKD male patients is higher (at $22 \mathrm{mg}$ to $20 \mathrm{mg}$ ) from recommended level $(9 \mathrm{mg}$ ) and in female patients 17 mg in FU. KDIGO 2012 Clinical Practice Guideline for the Evaluation and Management of Chronic Kidney Disease recommended that individuals with CKD receive expert dietary advice and information in the context of an education program, tailored to severity of CKD and the need to intervene on salt, phosphorus, potassium, and protein intake where indicated [1].

\section{Vitamins}

Dietary water soluble vitamins (tiamin, niacin, pyridoxine, folic acid, pantothenic acid, biotin, vitamin C) intake increased significantly in the female patients groups and remained in the recommended level in FU, but in male patients groups were found non-significant changes in FU. Dietary vitamin D intake increased significantly in female patients groups and remained under the recommended level in FU $(4.0 \mu \mathrm{g})$, but in male patients groups were found non-significant changes in FU $(3.5 \mu \mathrm{g})$. Dietary vitamin E content was in the recommended range in male and female patients groups (recommended range is $8 \mathrm{mg}$ ). KDIGO 2012 Clinical Practice Guideline for the Evaluation and Management of Chronic Kidney Disease suggest not prescribing routinely vitamin D supplements or vitamin D analogs, in the absence of suspected or documented deficiency, to suppress elevated PTH concentrations in people with CKD not on dialysis [1,20, and 21]. Normal renal diet, dietary intervention, intensive nutritional counselling and physical activity can help to avoid the appearance of chronic transplant nephropathy $[22,23]$. 


\section{CONCLUSION}

The routine monitoring of the patient after the kidney transplantation is performed according internationally recognized treatment instructions (K/DOQI Clinical Practice Guidelines for Chronic Kidney Disease, 2002; KDIGO. Kidney Disease: Improving Global Outcomes, 2012). The FFQ revealed that the patients consumed different foodstuffs at different frequencies, but there was a tendency to excessive consumption of foodstuffs rich in proteins and carbohydrates. To consumption of fat-rich foodstuffs a tendency of decrease was shown. The consumption of vegetables and fruit was modest compared to Estonian food and nutrition recommendations. A healthy diet, avoiding excessive amounts of alcohol and regular exercise can reduce the chance of developing of chronic transplant nephropathy. Intensive nutritional counselling and dietary therapy is always adjusted by the transplant team together with an experienced dietitian. Counselling plays a key role after the kidney transplantation in order to improve the patients' nutritional habits to avoid unbalanced and excessive food consumption if the patient has a tendency to weight increase.

\section{REFERENCES}

1. Kidney Disease: Improving Global Outcomes (KDIGO) CKD Work Group (2013). KDIGO 2012 Clinical Practice Guideline for the Evulation and Management of Chronic Kidney Disease. Kidney Inter, Suppl, 3, 1-150.

2. National Kidney Foundation. (2002). K/DOQI Clinical Practice Guidelines for Chronic Kidney Disease: Evaluation, Classification and Stratification. Am J Kidney Dis, 39, 2, Suppl 1, 1-266.

3. PEP 6305. Measurement in Health and Physical Education. Topic 15: Measuring Diet and Nutrition (http://grants.hhp.uh.edu/doconnor/PEP6305/Section 15.html).

4. Kiisk L., Ots-Rosenberg M., Kaarma H. (2010). Pecularities of Nutrition of Kidney Transplant Patients. Papers on Anthropology, XIX, 180-202.

5. Kiisk L., Rosenberg M., Kaarma H. (2009). Correlation analysis between variables of body build and food consumption of energy, macro- and micronutrients calculated by 3 -day menus in kidney transplant patients. Papers on Anthropology, XVIII, 201-213.

6. Kiisk L. (2002). Ravitoitlustamine. Treatment diets. Tartu, 1-222.

7. Tervisekaitsenõuded toitlustamisele tervishoiu- ja hoolekandeasutuses. Regulation No. 131, Health Protection Requirements for Nutrition in Health Care and Social Welfare Institutions. Estonian Ministry of Social affairs. RTL 2002, 131,1918 
8. Kiisk L., Rosenberg M. (2010). Toitumissoovitused kroonilise neeruhaiguse süvenemise ennetamisel.

9. Kiisk L., Kaarma H., Ots M. (2008). Treatment Diets in Estonian Health Care Institutions. Medicina, 577-584.

10. Eesti Toitumis- ja toidusoovitused. Estonian Nutrition Recommendations and Food Based Dietary Guidelines. (2006). Eesti Toitumisteaduse Selts, Tallinn.

11. Guida B., Trio R., Lacetti R., Nastasi A., Salvi E., Perrino N. R., Caputto C., Rotaia E., Federico S., Sabbatini M. (2007). Role of dietary intervention on metabolic abnormalitis and nutritional status after renal transplantation. Nefrol Dial Transplant, 22, 3304-3310.

12. Bernardi A., Biasia F., Piva M., Poluzzi P., Senesi G., Scaramuzzo P., Garizzo O., Stoppa F., Cavallaro B., Bassini S., Bucciante G. (2000). Dietary protein intake and nutritional status in patients with renal transplant. Clin Nephrol, 53, suppl 3-5.

13. Ryan K.J., Casas J.M., Mash L.E., McLellan S.L., Lloyd L.E., Stinear J.W., Plank L.D., Collins M.G. (2014). The effect of intensive nutrition interventions on weight gain after kidney transplantation: protocol of a randomised controlled trial. BMC Nephrology, 9, 15-148.

14. Patel M.G. (1998). The effect of dietary intervention on weight gains after renal transplantation. J Ren Nutr, 8, 137-141.

15. Mitch W.E. (2000). Dietary therapy in uremia: the impact on nutrition and progressive renal failure. Kidney Int, Suppl, 75, 38-43.

16. Lopes I.M., Martin M., Errasti P., Martinez J.A. (1999). Benefits of a Dietary Intervention on Weight Loss, Body Composition and Lipid Profile After Renal Transplantation. Nutrition, 15, 7-10.

17. Hines L. (2000). Can low-fat/cholesterol nutrition counselling improve food intake habits and hyperlipidemia of renal transplant patients? J Ren Nutr., 10(1), 30-35.

18. Zelle D.M., Kok T., Dontje M.L., Danchell E.I., Navis G., van Son W.J., Bakker S.J., Corpeleijn E. (2013). The role of diet and physical activity in post-transplant weight gain after renal transplantation. Clin Transplant, 27, 484-490.

19. Morris C.D. (1997). Effect of dietary sodium restriction on overall nutrient intake. Am J Clin Nutr, 65 (2 Suppl), 687-691.

20. Lynch I.T., Eustace J.A., Plant W.D., Cashman K.D., O’Keefe M., Lordan S., Moloney R. (2007). Inadequate dietary calcium and vitamin D intakes in renaltransplant recipients in Ireland. J Ren Nutr, 17(6), 408-415.

21. Lichtenstein A.H., Kennedy E., Barrier P., Danford D., Ernst N.D., Grundy S.M., Leveille G.A., Van Horn L., Williams C.L., Booth S.L. (1998). Dietary fat consumption and health. Nutr Rev, 56(5 Pt 2), 3-19, discussion 19-28.

22. Tonstad S., Holdaas H., Gørbitz C., Ose L. (1995). Is dietary intervention effective in post-transplant hyperlipidaemia? Nephrol Dial Transplant,10, 82-85. 
23. Stenvinkel P. (2001). Malnutrition and chronic inflammation as risk factors for cardiovascular disease in chronic renal failure. Blood Purif, 19, 143-151.

Address for correspondence:

Liidia Kiisk

Tartu University Hospital

50406 L. Puusepa str. 8

Tartu, Estonia

E-mail: liidia.kiisk@kliinikum.ee 